\title{
CONSTITUIÇÃO DA AUTONOMIA NO PROCESSO DE PRO- DUÇÃO DA PESQUISA NA PÓS-GRADUAÇÃO STRICTO SENSU
}

\author{
THE CONSTRUCTION OF AUTONOMY IN THE PROCESS OF RESEARCH PRO- \\ DUCTION IN POST-GRADUATION STRICTO SENSU
}

\author{
CONSTITUCIÓN DE LA AUTONOMÍA EN EL PROCESO DE PRODUCCIÓN DE \\ LA INVESTIGACIÓN EN EL POSGRADO STRICTO SENSU
}

\author{
Gislaine Aparecida Rodrigues da Silva Rossetto \\ Professora Doutora do Departamento da Metodologia de Ensino (MEN) do curso de Pedagogia da \\ Universidade Federal de Santa Maria (UFSM). \\ gislainesilvarossetto@gmail.com \\ Doris Pires Vargas Bolzan \\ Professora Doutora do Departamento da Metodologia de Ensino (MEN) e do \\ Programa de Pós-graduação em Educação (PPGE), da Universidade Federal de Santa Maria (UFSM). \\ dbolzan19@gmail.com
}

\begin{abstract}
RESUMO: Esse artigo é parte da tese de doutorado cujo objetivo foi investigar a produção da atividade de estudo como processo desencadeador da autonomia na pesquisa na elaboração de dissertações de mestrado e de teses de doutorado. O foco foi identificar o percurso da atividade de estudo dos sujeitos investigados durante a elaboração de suas pesquisas e conhecer quais ações e operações estão implicadas na constituição da autonomia na pesquisa de cada um. A metodologia utilizada foi de natureza qualitativa e desenvolveu-se a partir da abordagem narrativa sociocultural (BOLZAN, 2002; BOLZAN et al., 2010; FREITAS, 2003; VYGOTSKI, 1997), a qual analisa a atividade narrativa dos sujeitos participantes a partir da realidade sociocultural. A coleta dos achados deu-se por meio de entrevistas semiestruturadas organizadas em tópicos guia. A partir dos excertos narrativos analisados foi possível compreender que a constituição da autonomia é uma construção particular, porém não solitária, pois se dá na interação com o outro; sua aprendizagem é gradativa e acontece ao longo de toda a vida. A autonomia na pesquisa constitui-se como uma espiral, a qual amplia-se a cada novo desafio. Por fim, evidenciamos, nesse processo, que a constituição da autonomia na pesquisa se dá mediante duas tensões: percurso da pesquisa e construção da autonomia, tempo de aprendizagem pessoal e tempo instituído para a pesquisa. Desse modo, esse estudo foi uma possibilidade de entendimento do que seja o processo de produção da pesquisa e a constituição da autonomia, tendo como mote a atividade de pesquisa.
\end{abstract}

PALAVRAS-CHAVE: Atividade de estudo. Autonomia na pesquisa. Produção da pesquisa. Pós-graduação stricto sensu.

ABSTRACT: This paper is part of the doctoral thesis which aimed to investigate the production of study activity as a triggering process of autonomy in research while elaborating master's dissertations and doctoral theses. It focused on identifying the course of the study activity of participants during the elaboration of their studies, and acknowledge which actions and operations are implied in their construction of autonomy in research. The study used a qualitative methodology and was carried out with the sociocultural narrative approach (BOLZAN, 2002; BOLZAN et al., 2010; FREITAS, 2003; VYGOTSKI, 1997), which analyzes the narrative activity of participants from their sociocultural reality. The collections were carried out through semi-structured interviews arranged into guide topics. From the narrative excerpts analyzed, it was possible to understand that the construction of autonomy is particular, although not solitary, once it happens through the interaction with others; and that its learning is gradual and continuous. The autonomy in research is like a spiral, which broadens at every new challenge. Finally, we evidenced in this process that the construction of autonomy in research happens through two tensions: course of study and construction of autonomy, time of personal learning and time established for research. Thus, this study was a way to understanding the process of research production and the construction of autonomy, taking into account the research activity.

KEYWORDS: Study activity. Autonomy in research. Research production. Stricto sensu Postgraduation.

Artigo recebido em janeiro de 2015

Aprovado em março de 2015

Cad. Pes., São Luís, v. 22, n. 1, jan./abr. 2015 
RESUMEN: Ese artículo es parte de la tesis de doctorado que trae como objetivo investigar la producción de la actividad de estudio como proceso motivador de la autonomía en la investigación, en la elaboración de disertaciones de maestría y de tesis de doctorado. El foco fue identificar la trayectoria de la actividad de estudio de los sujetos investigados durante la elaboración de investigaciones y conocer cuales acciones y operaciones están implicadas en la constitución de la autonomía en la investigación de cada uno. La metodología utilizada fue de naturaleza cualitativa y se desarrolló a partir del abordaje narrativa sociocultural (BOLZAN, 2002; BOLZAN et al., 2010;FREITAS, 2003; VYGOTSKI, 1997), que analiza la actividad narrativa de los sujetos participantes a partir de la realidad sociocultural. La recolección de los resultados fue por medio de entrevistas semi estructuradas, organizadas en tópicos guía. A partir de los fragmentos narrativos analizados fue posible comprender que la constitución de la autonomía es una construcción particular, pero se da en la interacción con el otro; su aprendizaje es gradual y ocurre a lo largo de toda la vida. La autonomía en la investigación se constituye como una espiral, que se amplía a cada nuevo reto. Por fin, evidenciamos, en ese proceso, que la constitución de la autonomía en la investigación se da a través de dos tensiones: trayectoria de la investigación y construcción de la autonomía, tiempo de aprendizaje personal y tiempo instituido para la investigación. De ese modo, ese estudio fue una posibilidad de entendimiento de lo que sea el proceso de producción de la investigación y la constitución de la autonomía, teniendo como tema la actividad de investigación.

PALABRAS CLAVE: Actividad de estudio. Autonomía en la investigación. Producción de la investigación. Posgradostricto sensu. 
CONSTITUIÇÃO DA AUTONOMIA | Gislaine A. R. da Silva Rossetto e Doris Pires Vargas Bolzan

\section{1 | INTRODUÇÃO}

No âmbito da educação, em especial, no que se refere à formação docentes dos diferentes níveis, seja na Educação Básica e na Superior, presenciamos a necessidade de desenvolvermos a capacidade de trabalhar com os conhecimentos apreendidos e as informações adquiridas, seja no campo teórico ou prático de nossa atuação profissional como, também, no campo social, econômico e político. Essas circunstâncias exigem dos sujeitos certa dose de autonomia, frente aos desafios e dilemas próprios do cotidiano da sala de aula ou fora dela. Nesse sentido, a aprendizagem da autonomia, isto é, a aprendizagem da capacidade de fazer escolhas de forma independente e consciente, tanto para si mesmo como para a sua coletividade, se faz imprescindível. Compreendemos que a autonomia é algo que se aprende e se desenvolve ao longo da vida, porém, existe a necessidade de ter espaços e condições para que o sujeito possa constituí-la.

$\mathrm{Na}$ concepção de Hegel atribuir autonomia a um sujeito não significa possuir liberdade ilimitada. Segundo o autor, o exercício desse atributo pelo sujeito "vem acompanhado de níveis de mediação, a começar pela família, como primeira base ética do Estado. Ora, mediação significa limitação, mas também, garantia de realização" (WEBER, 2010, p. 75). Quanto à ética, Hegel refere-se a ter consciência de que diante de todo direito temos um dever e frente a todo dever temos um direito. Assim, exercer o direito de ter autonomia envolve reconhecer as leis e as instituições sociais, na medida em que ambas são criações de vontades livres do conjunto de sujeitos que compõem essa mesma sociedade. Por essa razão, a liberdade do Homem se realiza por meio e no interior de cada instituição (WEBER, 2010).

Entretanto, Hegel (2010) expressa que há de se reconhecer a diferença entre liberdade e livre arbítrio. A primeira é a vontade livre mediada e reconhecida pelas instâncias que a medeiam. Liberdade não é o mesmo que fazer o que deseja, se assim fosse seria não conhecer e reconhecer as instâncias mediadoras (família, Estado, Igreja etc.) através das quais transitam a vontade livre, ou seja, o direito, a moralidade e a eticidade. Já o livre arbítrio, é também vontade livre, porém, imediata, no sentido de ser sem mediação. É um momento da liberdade, mas não a liberdade em sua totalidade. Weber (2010) explica o arbítrio por ser vontade imediata que precisa de reconhecimento. Nesse sentido, dizemos que tal reconhecimento se constitui pela mediação das instâncias sociais.

Weber (2010) ainda coloca que o indivíduo se afirma como pessoa ao mesmo tempo em que afirma sua vontade autônoma. Assim, a autonomia pressupõe o reconhecimento e este, por sua vez, pressupõe a liberdade. Por outro lado, o termo autonomia também está ligado à ideia de participação social e ampliação da participação política acerca da descentralização e desconcentração do poder; à ideia de construção da democracia, na qual uma sociedade possui a capacidade de se reger por si mesma, ter liberdade de elaborar suas próprias leis (MARTINS, 2002). Ainda de acordo com este autor, no campo político, o estudo do exercício e elaboração da autonomia remete ao entendimento da construção da

[...] noção de democracia desde Rousseau, para quem, o princípio inspirador do pensamento democrático sempre foi a liberdade entendida como autonomia, isto é, como a capacidade de uma sociedade de dar leis a si própria, promovendo a perfeita identificação entre quem dá e quem recebe uma regra de conduta, eliminando, dessa forma, a tradicional distinção entre governados e governantes sobre a qual fundou-se todo o pensamento. (MARTINS, 2002, p. 10). 
Entretanto, a existência de regras de condutas em consenso com maioria, saindo de cena a distinção entre governados e governantes, não é o suficiente para que a democracia se estabeleça. É necessário fornecer alternativas possíveis de serem concretizadas para os sujeitos que venham a ser chamados a fazerem suas escolhas. Porém, para fazer escolhas é necessário conhecer, tornar-se um homem esclarecido, com o entendimento das coisas que acontecem consigo e ao seu redor. Segundo Kant (1783), o sujeito não deve se submeter à tutela de outrem, ou seja, o sujeito deve pensar por si mesmo no lugar de permitir que outro pense por ele.

Ser um sujeito esclarecido "significa a saída do homem de sua minoridade, pela qual ele próprio é responsável" (KANT, 1783, p. 1). Para sair da minoridade deve utilizar-se do saber e da coragem de servir-se da própria razão, pois é desse modo que o sujeito alcança sua maioridade. Kant reconhece que não é tão simples assim para o sujeito buscar o seu esclarecimento e, consequentemente, alcançar a sua maioridade. Ao contrário, conscientiza-nos que é penoso posto às várias quedas que podemos levar neste percurso. Contudo, é um risco que vale a pena correr, visto que são nas quedas que podemos aprender e seguir em frente.

Kant (1783) elucida que, como intelectuais, temos o dever de esclarecer, de manifestar nossos pensamentos, a isto ele denomina de uso público da razão. Porém, durante o exercício de uma função profissional devemos ser mais cautelosos ao expressar nossas ideias e entendimentos, posto que, neste caso, representamos uma instituição, a isto chama de uso privado da razão. Kant (1783), diz que é preciso estimular as pessoas a fazerem uso da razão, bem como ter a coragem de servir de seu próprio entendimento.

$\mathrm{Na}$ educação, isto significa oferecer condições para que o estudante tenha coragem e liberdade de pensar e de se expressar por si mesmo. Nesta perspectiva, o docente tem a função de auxiliar o seu discente a sair da minoridade e alcançar a maioridade. O que não quer dizer que este docente não tenha coisas para ensinar ao seu discente e vice-versa.

A presença do tutor é necessária, posto que é "difícil para todo o homem tomado individualmente livre-se dessa minoridade que se tornou uma espécie de segunda natureza. Ele se apegou a ela, e é então realmente incapaz de se servir de seu entendimento, pois não deixam que esse o experimente jamais" (KANT, 1783, p. 2). Ainda a este respeito Kant diz que o caminho para o esclarecimento, onde o entendimento é uma condição necessária, é longo uma vez que fazer o sujeito pensar por si mesmo é algo complexo, porém não impossível.

Nesse momento, poderíamos perguntar: Qual é a relação do que seja o esclarecimento em Kant com a conquista da autonomia? Podemos responder que a partir do momento que o sujeito passa a entender algo (fenômeno, conhecimento ou objeto) torna-se esclarecido. E, segundo ele, quando o Homem se esclarece, no sentido de entender as coisas por si mesmo, chega-se a seu estado de maioridade. Compreendemos que o caminho para alcançar a maioridade requer a presença de alguém mais especializado e experiente, ou seja, o Homem ainda precisa usufruir da tutela do outro para continuar a seguir sendo esclarecido, mesmo que seja por tempos determinados, posto que é este um processo contínuo. Assim, a nosso entendimento do que seja esclarecimento em Kant estar relacionado o conceito de autonomia.

Nesse sentido, o Programa de Pós-graduação stricto sensu seria um dos tempos e lugares nos quais o sujeito continuaria a ter espaço para usufruir e compartilhar com um conjunto de pessoas, docentes e discentes, conhecimentos e procedimentos de estudo e pesquisa que o auxiliassem a compreenderem não somente seu próprio objeto ou sujeito/s de pesquisa, como também a si mesmos como profissional e pessoa. Seria um dos tempos e dos lugares para continuar o processo de esclarecimento e de desenvolvimento da autonomia.

Na Pós-graduação stricto sensu, espera-se que essa atitude autônoma seja algo já constituído nos estudantes que nela chegam, entretanto ela ainda consiste em um dos principais desafios a 
CONSTITUIÇÃO DA AUTONOMIA | Gislaine A. R. da Silva Rossetto e Doris Pires Vargas Bolzan

ser alcançado seja no campo acadêmico ou no campo profissional (MARTíN, s.d.). Soares e Cunha (2010, p. 379-380) nos dizem que na etapa mencionada ainda temos o desafio de

[...] enfrentar a fragilidade das competências prévias para os estudos superiores, evidenciadas por parte de um grande contingente de estudantes, envolvendo a capacidade de leitura e interpretação de textos, de produção autônoma do pensamento reflexivo e das ferramentas necessárias para as aprendizagens complexas.

Observamos que os estudantes chegam aos cursos de mestrado e doutorado ainda com fragilidades a superar. Sendo que muitas delas são lacunas que os acompanham desde a Educação Básica. Isso posto, interessou-nos focar nossos estudos na capacidade desses sujeitos em gerenciarem sua própria aprendizagem para buscarem conhecimentos e para realizarem ações capazes de operacionalizar suas pesquisas. Inicialmente chamamos essa capacidade de autonomia investigativa. Partimos do princípio de que a autonomia investigativa pode ser aprendida, construída e reconstruída por meio de uma atividade específica concebida, a partir da teoria sócio-histórica, como atividade de estudo (VYGOTSKI, 1997; DAVÍDOV; MÁRKOVA, 1987).

\section{2 | SOBRE O PERCURSO DA PESQUISA APRESENTADA}

A pesquisa que apresentamos nesse artigo é parte da tese de doutorado de uma das autoras cujo objetivo foi investigar a produção da atividade de estudo como processo desencadeador da autonomia na pesquisa no processo de elaboração de dissertações de mestrado e de teses de doutorado. Para esse texto temos como foco apresentar os resultados que obtivemos a partir da análise dos achados no que se refere à constituição da autonomia dos estudantes de mestrado e doutorado em suas investigações, ou seja, a autonomia na pesquisa.

O contexto investigativo desse trabalho foi o Grupo de Pesquisa e Formação de Professores: Ensino Básico e Superior (GPFOPE), vinculado ao programa de Pós-graduação em Educação (PPGE) em nível stricto sensu, do Centro de Educação (CE), da Universidade Federal de Santa Maria (UFSM). Nossos sujeitos de pesquisa foram duas estudantes de mestrado e três estudantes do doutorado. A coleta dos achados deu-se por entrevistas semiestruturadas, sendo estas elaboradas em 3 blocos a partir de tópicos guia. As entrevistas semiestruturadas foram audiogravadas e, posteriormente, transcritas em seu conteúdo literal para serem analisadas posteriormente pela pesquisadora, antes, porém, foi entregue a cada uma das participantes para realizarem a leitura e aprovação da mesma. Durante as análises, sentimos necessidade de esclarecer ou de complementar algumas das informações fornecidas. Para tanto, utilizamos a análise de memoriais descritivos da trajetória profissional elaborados pelas colaboradoras na ocasião da seleção de doutorado ou provenientes do próprio projeto de pesquisa.

A abordagem metodológica utilizada foi de natureza qualitativa e desenvolveu-se a partir da abordagem narrativa sociocultural (BOLZAN, 2002; BOLZAN et al., 2010; FREITAS, 2003; VYGOTSKI, 1997), na qual se analisa a atividade narrativa dos sujeitos participantes a partir da realidade sociocultural. É uma abordagem que implica a compreensão do processo de transformação explicitado pelos colaboradores acerca de suas ideias manifestando a subjetividade e a objetividade das relações sociais por eles experienciadas (BOLZAN, 2006). Assim, conhecer e analisar as narrativas dos sujeitos pesquisados permitiu-nos descrever detalhadamente os percursos de produção de suas pesquisas, bem como a constituição de suas autonomias neste processo investigativo. 


\section{3 | A CONSTITUIÇÃO DA AUTONOMIA NA PESQUISA PELOS ESTUDANTES DE MESTRA- DO E DOUTORADO}

Para compreender constituição autonomia das estudantes de mestrado e doutorado em suas investigações, buscamos identificar o percurso da atividade de estudo de cada sujeito envolvido neste trabalho, durante a elaboração de suas pesquisas e conhecer quais ações e operações estão envolvidas no processo de constituição de sua autonomia na pesquisa.

Para que a autonomia na pesquisa seja alcançada, é preciso fazer com que o sujeito experiencie situações desafiadoras nas quais possa se posicionar, ou seja, tomar para si uma direção no processo de sua atividade de pesquisa. Entretanto, não basta unicamente saber decidir e justificar suas escolhas, é preciso saber se autoavaliar e se auto-orientar continuamente. Isto exige do sujeito manter-se em constante aprendizagem, em permanente processo de aprender a aprender. (MONEREO; POZO, [200-?]). Autoavaliar é realizar uma análise de si mesmo quanto ao próprio rendimento e domínio das ações e operações efetivadas e o quanto elas auxiliaram a alcançar os objetivos. E, auto-orientar é redimensionar as necessidades e motivos, ações e operações e, com isto um novo processo de atividade de estudo se estabelece (DAVÍDOV; MÁRKOVA, 1987). A partir dessas duas ações, o sujeito toma consciência de suas limitações e potencialidades.

A tomada de consciência das limitações e das potencialidades é a percepção do sujeito acerca de suas fragilidades e de seus potenciais no percurso da produção de suas pesquisas. Tomar consciência significa reconstituir em nível mental as atividades que executa, representa a capacidade do homem em conhecer e compreender o seu espaço social e o mundo dos objetos passíveis de também serem conhecidos e analisados (VYGOTSKI, 2010).

Desse modo, evidenciamos que a capacidade das colaboradoras de perceberem suas limitações e potencialidades e de se autoavaliarem foram configuradas de distintos modos, como: repetir para si mesma e falar para o outro sobre os conhecimentos e procedimentos; dialogar com as colegas de grupo, as fizeram perceber diferentes formas de pensar e de se organizar na pesquisa, e as conversas com a professora-orientadora possibilitavam reafirmar ou rever as tomadas de decisões, entre as diferentes ações e operações realizadas para efetivação do desenvolvimento da pesquisa. Observemos os excertos:

Eu preciso falar, eu sou alguém que fala muito enquanto penso (risos) quando eu estava estudando a Agnes Heller acho que ninguém mais aguentava eu falar da Agnes Heller, nem que seja para me ouvir só. [...] a própria ideia de poder discutir essas narrativas, o quanto o que eu sou capaz de captar é diferente da tua leitura [...] e isso não é muito fácil e aprender trabalhar em grupo é muito complicado! Porque é tu sair de si e ir em direção ao outro e produzir uma terceira coisa (S1).

[...] no momento da escrita do projeto eu não aprofundei o que era necessário porque não consegui perceber, seja por própria fragilidade que eu ainda não tinha compreendido, aí nesse momento foram coisas que a banca pontuou e que comecei a perceber de outra forma [...] esse trabalho com os colegas e em aula também [...] a aula do seminário de Vygotski, ouvir as outras pessoas falando, principalmente a professora [...] aí eu comecei a perceber quanta coisa eu tinha que explorar e não explorei em relação aos conceitos, aos termos [...] e que só consigo perceber quando ouço outras pessoas falando, porque individualmente, eu fazendo a leitura, talvez eu não consiga perceber porque para mim aquilo já está tão costurado que a gente precisa do outro para conseguir perceber (S5).

[...] uma única vez sai em conflito que foi nas dimensões conclusivas, ela [professora-orientadora] sinalizou mais ou menos como deveria ser, porque eu não conseguia entender a diferença entre resultado e dimensões conclusivas, para mim era uma coisa única! Ela tentou sinalizar as 
distinções. [...] Numa segunda orientação ela disse: "Bom, ainda está muito insipiente, não trata ainda das dimensões conclusivas, é para, além disso! Tu tens que refazer!" [...] Fui para casa. Reviso o texto, bom virou o "samba do crioulo doido", porque ela tinha me orientado de uma forma e eu tinha entendido de outra [...] (S4).

A circunstância da produção da pesquisa possibilitou para os sujeitos investigados um espaço para a reflexão, o estudo e a aprendizagem seja no âmbito de sua formação docente ou de sua formação para pesquisa. No doutorado se evidencia um maior grau de excelência quanto à produção de conhecimento para o campo no qual se investiga, se comparado ao mestrado. Esse nível de excelência emerge da cultura acadêmica instituída nesta etapa de formação e a qual se traduz em angústia para os estudantes desta etapa da Pós-graduação stricto sensu. Isso se evidencia nas narrativas que seguem:

[...] eu pensava assim "Eu não sei o que é produzir uma tese! Eu estou descobrindo" [...] Porque eu não tenho clareza! Inclusive não tenho clareza se o caminho que optei é um caminho legal [...] digo no sentido de organização [...] quando perguntam para gente "O que é produzir essa tese?" E tem que ser um produto de excelência há uma cobrança em cima de ti. Tu estás no doutorado! Esse título traz um monte de coisa. Eu lembro quanto tempo eu fui dizendo para todo mundo "Não dizem que vocês são doutorandas!" Porque parece que quando tu colocas aquela "doutoranda" na frente, tu vai apresentar alguma coisa, aquilo te coloca assim uma responsabilidade que tu se assusta, porque tu não sabes se tem perna para tudo aquilo! [...] É uma posição que está relacionada com o domínio de um campo. Então, quando tu dizes que está frágil, tu estás te fragilizando! Então tu não podes dizer que não sabe coisas! (S1).

Há três anos eu leio sobre formação de professores! Nenhum autor da minha dissertação de mestrado faz parte da minha tese! [...] Então eu sinto que eu ainda estou muito incipiente em toda essa discussão, por isso ainda não me sinto capaz! [...] Percebo que quando tento discutir algumas coisas as pessoas e elas colaboram, a minha orientadora colabora inclusive me dando sugestões de leituras que eu posso fazer para me ajudar, mas eu não sinto que esse diálogo [com os autores de base] ainda seja possível, porque eu reconheço ou eu me cobro, talvez eu até pudesse falar, mas eu ainda não me reconheço capaz! (S3).

Emerge das narrativas que as colaboradoras, em alguns momentos, ainda consideravam incipientes a apropriação de alguns conteúdos teóricos importantes para suas pesquisas, mesmo depois de um considerável tempo de estudo. Esta situação causava-Ihes insegurança e dificultava o desenvolvimento da autonomia em suas investigações. Porém, elas se encontravam a caminho desta constituição, uma vez que já haviam tomado consciência de suas limitações e potencialidades. $E$, tal tomada de consciência requereu de nossas colaboradoras romperem com as suas concepções, ideias iniciais, abrindo-se, assim, para novas aprendizagens.

Autoavaliar-se é efetuar uma reflexão de si mesmo quanto ao seu rendimento, clareza das ações e operações e a capacidade de mensurar o quanto estas o auxiliam para alcançar os objetivos. Reorientar ações e operações é ser capaz de gerenciar a si mesmo durante processo de aprendizagem que terá pela frente, a fim de concluir o desafio a que se propôs, no caso, a produção da pesquisa. Chamamos esta mobilização de momentos de rupturas.

Os momentos de rupturas manifestados pelos sujeitos pesquisados localizaram-se nas ações e nas operações em que foi preciso refazer seus escritos, uma vez que já tinham fechado suas ideias. Essas rupturas causavam-Ihes conflito interno constituído pelo embate de duas posições: a resistência em reelaborar o que parecia pronto e a abertura para novas possíveis construções, vejamos:

[...] eu luto muito para construir as coisas que eu construo e não que seja diferente de outras [...] quando eu tenho que refazer um caminho, isso para mim é muito duro! Eu tenho que desconstruir 
guilhotinar aquilo e começar tudo de novo. [...] Então agora a minha escrita eu me conheço e eu sei, eu ainda não sou capaz e lidar comigo mesmo como eu deveria, já tenho consciência de que quando tomo uma decisão e faço tais escolhas e alguém me diz "Não, não é por aí!" Até eu assumir aquilo e fazer outro caminho, levo tempo. [...] mas tem que ter abertura e humildade, porque senão tu te fechas e não constrói (S1).

[...] eu tive que rever a fundamentação teórica: limpei, limpei, limpei, e dói, dói muito tirar dez. Sabe que dói muito tirar um parágrafo, agora tu imaginas tirar 8, 10 páginas, 12 páginas [...] Eu não me desesperei [...] teve só um dia que eu quase chorei, que foi quando a orientadora reorganizou as minhas categorias, porque para mim elas estavam muito certas na minha cabeça, estava tudo muito fechadinho [...] Sabe e até eu assimilar, compreender aquela reorganização leva tempo! (S4).

Um de nossos sujeitos pesquisados manifestou incertezas frente às novas possibilidades trazidas nas problematizações apontadas pela banca, contudo estava disposta a rever os encaminhamentos iniciais. Assim, face às sugestões de redirecionamentos expressadas pela banca de qualificação de sua pesquisa, identificamos mais um momento de ruptura, na medida em que provocou reavaliação das ações e operações e, consequentemente, reorientou parte do percurso do desenvolvimento da pesquisa. Isso pode ser constatado no excerto que segue:

[...] estou vendo que o meu trabalho está se desmanchando! O que eu me matei para fazer, quase isso, porque às vezes as pessoas não querem nem saber se tu estás doente ou não está, as coisas são assim que funciona. Quando tu tens resposta para dar em um período " $x$ " e aí eu vejo que eu estou desconstruindo. [...] estou indo para um caminho que, talvez, não seja esse, não sei! [...] Mas hoje eu reconheço que quatro anos é pouco e a qualificação é o começo do trabalho! [...] (S3).

Com os excertos apresentados até o momento podemos dizer que alcançamos a constituição da autonomia na pesquisa à medida que refletimos sobre os elementos constituintes de nossa atividade de pesquisa, de maneira a sermos capazes: de perceber nossos limites, mas também nossas potencialidades e de poder [re] orientar os elementos que compõem esse tipo de atividade de estudo de forma cada vez mais independente. Esse tipo de mobilização para realizar sua atividade de pesquisa que leva o sujeito a refletir, a organizar e a sistematizar o seu próprio processo de aprendizagem possibilita o que denominamos de gerenciamento da aprendizagem, ou seja, a capacidade de pensar, coordenadamente, sobre o próprio caminho para aprender e aprender a aprender.

Desse modo, o gerenciamento da aprendizagem, consistiu em detectar e compreender as necessidades e motivos que levaram os sujeitos investigados a estabelecerem novos processos de atividade de estudo no interior de uma atividade mais ampla: a atividade de pesquisa. Vejamos o excerto:

[...] a minha caminhada [nas disciplinas do curso] não acompanhou com a escrita [da pesquisa] assim, "Ah já estou nas disciplinas, já vou escrevendo!" Não. Primeiro foram essas leituras, teve um tempo que eu me determinei naquilo. Estive bem distante, mais solitária, produzindo. Aí de novo fui para as leituras, fui para o campo e o campo te direciona a outras leituras e nesse momento eu estou no mesmo que eu estava lá no início! Chega a ter um monte de caminhos e eu não sei para que lado eu vou. Lá eu me desesperei mais, agora eu vi que é um processo que a gente passa. Já estou mais tranquila [...] Porque tem que fazer: fazendo as entrevistas, escrevendo, escutando, daqui a pouco ele sai! (S2).

Os primeiros 6 meses de mestrado eu fiquei em crise [...] Então eu tive que ler muito até eu entender, claro que entendo muito superficialmente, para eu entender o porquê daquilo não me servir. [...] Os estudos culturais eles olham por questões políticas e filosóficas. E eu não queria olhar 
para questões políticas e filosóficas [...] Eu queria olhar as questões práticas e cotidianas que ajudam o professor a se constituir [...] Olhando para esse fazer que é prático, do chão da escola [...] Então quando eu descobri essa coisa "simples" [...] isso bastava [...] As decisões sempre estavam amparadas na escolha epistemológica, na escolha dos autores!” (S4).

Emergem das falas dos sujeitos que a tomada de consciência e a condução de suas próprias formas de aprender aconteceram em distintos momentos no decorrer da produção da pesquisa. Outro elemento observado, no gerenciamento da aprendizagem, foi o sentimento de solidão na produção da pesquisa, o qual esteve mais explícito em algumas. Isso é evidenciado nas falas que seguem:

[...] a minha discussão mais densa do doutorado, tá sendo solitária. Tá sendo solitária. Que inclusive a orientadora não leu ainda a Agnes Heller. Isso está sendo solitário. Depois nós vamos descobrir, depois da banca, porque até na banca quem já leu é uma pessoa. Se ela vai dizer que eu fiz um entendimento completamente equivocado ou não (S1).

O processo solitário, eu imagino que todos têm, por quê? Porque a pesquisa ela é tua, tu não vai ter o teu orientador ao teu lado para escrever contigo um parágrafo ou outro parágrafo. Eu imagino que se tu tiveres uma necessidade muito grande pode ser que aconteça isso, pode ser que o teu orientador sente ao teu lado e te ajude a colocar a tua ideia no papel. [...] este campo de saber era meu e não da minha orientadora, ela compartilhava comigo e eu acredito que muitas coisas eu estava aprendendo e ela também e nós aprendemos juntas (S4).

Então a todo tempo é decidir o que é que tem que estudar, o que é que eu vou fazer e o medo de estar optando por um lado que talvez não seja o melhor, essa solidão muitas vezes que você acha, já aconteceu assim de eu ler um livro e achar que ele respondia tudo na minha tese, meu Deus, era tudo que eu precisava. Daqui um pouquinho eu comecei a pensar "Mas eu estava louca, como que isso aí... nada a ver. A resposta não é imediata, a resposta é uma construção e talvez eu nunca tenha!" Então, reconhecer, às vezes, [...] é muito difícil, isso me dá uma angustia, dá uma solidão [...] Essa é a dificuldade! Então exige que eu defina, tome uma atitude que me responsabilize inteiramente! (S3).

[...] o início da minha organização, eu tenho que ter uma base de alguém que já escreveu, por exemplo, na dissertação eu tive que ler antes dissertações que tinham assuntos próximos para que conseguir entender que caminho foi aquele que a pessoa fez como ela sistematizou o referencial, então isso é a organização [...] Eu vejo que eu não consigo ainda ter essa organização [organização da atividade de estudo] de dizer olha: "Eu primeiro faço isso, depois isso e isso me ajuda". Eu vejo que muita coisa eu tenho construído também vendo o que as colegas fazem, porque pra mim ainda é muito difícil começar a produzir (S5).

Apesar do sentimento de solidão, consideramos que as colaboradoras conseguiram assumir para si a tarefa de estudo a ser desenvolvida, coordenando as ações e operações de sua atividade de pesquisa. Isto consistiu no gerenciamento de suas aprendizagens. Também fez parte deste gerenciamento pensar em operações que foram objetivadas/concretizadas mediante os seguintes procedimentos de pesquisa: a coleta dos dados, construção e análise das categorias e também, a própria estrutura de organização e sistematização do projeto ou do relatório de pesquisa.

Evidencia-se, também nos excertos, que o processo de transferência da consciência social para a individual auxiliou as colaboradoras a se autorregularem, isto é, a ordenação de si mesmas de modo a responsabilizarem-se sobre suas decisões e orientações a tomar (VYGOTSKI, 1997). Podemos considerar que a linguagem verbal teve função fundamental na transferência da consciência social - representada por um conhecimento construído e reconhecido como válido por uma sociedade, o novo conteúdo - para a consciência individual, a qual se esforça por compreender e legitimar para si o conhecimento reconhecido pela sociedade. 
[...] os colegas, a grande maioria, eu percebo que faz o caminho que eu estou fazendo, está buscando o que eu também estou buscando, se angustiando com o que eu também me angustio. E eu acho que a gente se coloca lado a lado quando, por exemplo, vou ler um texto e a gente pergunta para o colega "Você já leu? Que caminho você fez?" E sempre escuto com muita atenção, porque acho que escutando a gente aprende muita coisa, mas é um escutar que eu possa dialogar [...] Então, quando os meus colegas falam eu reconheço o caminho, porque também estou nesse caminho (S3).

Então a possibilidade de fazer uma entrevista, ouvir a entrevista e perceber o quanto tu produz uma interrupção, o quanto tu interfere [...] Então, a possibilidade de fazer a entrevista e ouvir a entrevista tu consegue produzir esse afastamento necessário para ti te olhar como pesquisador, como alguém que está entrevistando. Então, eu percebo que isso auxiliou na minha forma de conduzir a entrevista [...] (S1)

Oferecer ao pesquisador do curso de mestrado e doutorado a responsabilidade de tomada de decisão em seu processo investigativo se faz necessário para que ele sinta-se autor de seu trabalho e para que possa continuar motivado face aos desafios que terá pela frente. E delegar essa responsabilidade para o estudante de doutorado é inevitável. Sentir-se autor de seu processo investigativo é uma forma de manter latente o motivo pelo qual o sujeito, que investiga, ainda permaneça desejoso de prosseguir, sistematizando e concretizando as ações e operações que planejou alcançar. Contudo, isto não significa que, durante o percurso, não sejamos surpreendidos por conflitos internos das mais variadas naturezas.

Consideramos que foi justamente o conjunto de elementos como: a tomada de consciência, as decisões a tomar, a rupturas a realizar e o gerenciamento de aprendizagem que conduziram os sujeitos pesquisados a experienciar a transformação de si.

A transformação de si consiste nas mudanças que a experiência da produção da pesquisa imprime no sujeito tanto no âmbito pessoal como no âmbito profissional. Ela se constitui a partir da reflexão que se faz sobre os fatores que levaram o sujeito aos êxitos ou aos equívocos durante o percurso de pesquisa. E sua elaboração e/ou [re]elaboração dependerá do grau de consciência que o sujeito possui acerca do entendimento e das implicações que sua atividade de pesquisa imprimirá nele. Entre os dilemas que apresentados pelas colaboradoras no sentido de transformarem a si mesmas, o fator tempo foi o que afligiu, significativamente, a todas elas. A influência desse fator esteve presente em dois aspectos: no ritmo de aprendizagem de cada uma e no período de formação instituído pelo Programa de Pós-graduação stricto sensu. Vejamos o que emerge dos excertos:

O tempo do doutorado é um tempo de experienciar uma criação, mas é uma criação de si, pode até ser que esse produto, eu sei que a gente tem uma obrigatoriedade que esse produto tenha que ter uma criação do ponto de vista acadêmico. Hoje talvez seja até um mecanismo de defesa, eu não sei se o que eu estou produzindo é uma criação para academia, para mim é uma criação absurda, porque eu avancei [...] porque eu conheci coisas que eu desconhecia! [...] E a gente tem um produto, a gente terá um produto que é material, que é uma escrita, que é um relatório de uma pesquisa! Mas a gente não tem entendimento, talvez, do que isso repercute na vida da gente na totalidade: quem era a S1 que entrou há 4 anos atrás? E qual a S1 que vai sair? Isto não tem escrita e não tem trabalho que vai dar conta, não tem! (S1).

[...] a pesquisa de doutorado, ela está sendo dolorida, eu acho que não somente pela pesquisa, mas porque é um momento que também começa a se validar o conhecimento e a partir do momento que a gente pensa que sabe algumas coisas, outras perguntas bem inquietantes vão surgindo [...] A gente vê o mundo com outros olhos, as pessoas que estão ao redor e eu decidi comprar uma casa no campo durante o doutorado porque eu quero viver com a natureza, que res- 
CONSTITUIÇÃO DA AUTONOMIA | Gislaine A. R. da Silva Rossetto e Doris Pires Vargas Bolzan

ponde muito mais do que muitas outras teorias e pessoas! [...] a pesquisa impõe tempo, ela impõe limitações [...] Então você, com um foco numa resposta para uma academia e de um tempo ou de alguém que você tem que entregar um trabalho, você ata quatro anos, você mata o humano que você é, você compromete a relação com as pessoas [...] Até que ponto esse sujeito está bem para pesquisar? É o mal estar de pesquisa, não é o mal estar docente, mas é o mal estar de pesquisador! (S3).

[...] às vezes é doído [sobre a experiência da produção da pesquisa], só que esse doído não pode se transformar numa paranoia [...] um fardo e isso aí acho que tem muito a ver com o equilíbrio emocional da gente, que a gente também tem que trabalhar, por isso que eu digo, que a produção da tese não é só aprendizagem em relação à temática da tese que tu vai sair eu acho que é meio que equilibrado esse tanto da produção que tu vai sair em relação a temática da tese, como outras coisas que estão envolvidas na tua vida e que tu aprende no decorrer. Todo mundo que faz doutorado sai muito diferente e, realmente, sai muito diferente, porque tu tens que te colocar a aprender outras coisas, se tu não aprendes, toda a trajetória do doutorado vai ser só de vento. (S2).

Há a tensão entre o tempo instituído pela academia versus tempo necessário para a produção da pesquisa que é próprio para cada um. Estabelecer o equilíbrio entre esses tempos distintos foi um desafio a ser superado em cada uma das colaboradoras. Desse modo, foi necessário estabelecer e manter uma disciplina para o desenvolvimento da atividade de pesquisa. Isso significou ter uma rotina de trabalho, o que exigiu instituir a si mesmo compromisso para que ao final fossem alcançadas as metas de produção da pesquisa. Caso contrário, corria-se o risco do autoboicote, mesmo consciente da necessidade de prosseguir na atividade de pesquisa. Isso pode ser evidenciado na fala de S2:

É a tua própria cabeça, te disciplinar, [...] é no sentido de te colocar a produzir, porque eu acho que tem alguns momentos que a gente meio que bloqueia [...] pelo menos para mim, eu tenho que me determinar e me colocar como se fosse, alguém tivesse me mandando, tenho que me mandar a produzir, não interessa se vai sair bom ou ruim, mas tu vai escrever. Porque [...] depende da fase que eu estou, tenho uma tendência a fugir! Então, se não me coloco dessa maneira, de exigir isso, porque essa tendência a fugir é inicial [...] (S2).

Ao estabelecer uma disciplina e uma rotina de trabalho, nossa colaboradora se autodeterminava e seguia em frente em sua atividade de pesquisa, não interessava se os resultados eram positivos ou negativos, o que importava era manter a autodeterminação em prosseguir no sentido de alcançar as metas estabelecidas. Com isto, os sujeitos de nossa pesquisa passaram por uma experiência de tensão entre liberdade e livre arbítrio, aspectos que envolvem a constituição da autonomia do sujeito. Sendo que o livre arbítrio é entendido, nesse trabalho, como uma vontade imediata, que é determinada por uma contingência de fatos e de atribuições presentes seja no seu espaço de trabalho ou mesmo da vida pessoal capaz de atrair e de seduzir o sujeito. Já a liberdade, não é o mesmo que fazer o que desejamos, seu exercício acompanha mediações. A mediação referida significa garantia de realização e, não somente limitação ao sujeito como aparentemente possa sugerir. Assim, o livre arbítrio evidenciou-se quando surgiu a vontade de fugir devido às dificuldades de aprendizagens e frente à tomada de consciência de suas limitações. Porém, a liberdade manifestada não só pela conscientização individual, mas também influenciada e proporcionada pela troca de experiência com o outro fortalece o sujeito a prosseguir na produção de sua pesquisa, pois percebe que sua dor não é única.

Percebemos, nas análises dos excertos das narrativas, que foi mediante o enfrentamento das limitações, no sentido de superá-las e de investir nas potencialidades, que cada um dos sujeitos passaram a esclarecer e a conhecer o seu próprio processo de aprendizagem e com isto transfor- 
transformaram a si mesmos. Contudo dentro de um espaço de tempo restrito, instalou-se a contradição e a insegurança, visto que era necessário produzir resultados e o relatório de pesquisa dentro de um período com data limite para conclusão.

Para entendermos o que acontece nesse momento de contradição e insegurança, reportemo-nos aos estudos de Leontiev (1989) quando diz que a presença da contradição no sujeito é algo inerente à passagem do estágio que se encontra para um outro, a este momento dá-se o nome de crise. A crise é causada pelas características interiores de cada sujeito em desenvolvimento e pelas contradições que surgem entre ele e o seu ambiente. Assim, as exigências e as expectativas exteriores postas institucionalmente, em especial, aos estudantes do doutorado, junto às exigências e expectativas interiores destes próprios sujeitos, configuraram-se nos motivos de sofrimento durante o processo da produção da pesquisa e na constituição da autonomia de cada um dos envolvidos.

A autonomia do sujeito durante o seus fazeres da pesquisa é uma característica que pensamos ser naturalmente presente nos estudantes que chegam aos cursos de Pós-graduação em stricto sensu. Porém, esta característica ainda é um dilema a ser superado seja no campo acadêmico ou no campo profissional e como tal precisa não só ser objeto de aprendizagem desses sujeitos nessa etapa de ensino, como também objeto de investigação. Nesse sentido, nos colocamos no desafio de compreender se a atividade de pesquisa possibilitou a constituição da autonomia na produção das teses e das dissertações das colaboradoras, mas antes procuramos saber o que elas compreendiam por autonomia. De maneira geral, as colaboradoras manifestaram que constituição da autonomia é uma construção particular, porém não solitária. Não constituem a autonomia sozinha, ao contrário, necessitam da presença do outro para essa aprendizagem. Contudo, isto não significa ficar sob a tutela do outro, durante todos os momentos da produção da pesquisa e da constituição de sua autonomia nesse processo.

Nessa perspectiva, compreendemos que a autonomia é uma construção gradativa que acontece não somente durante uma determinada etapa do processo de aprendizagem, mas, sim, durante ao longo de toda a vida e, por essa razão poderemos vir a necessitar novamente da presença de outro mais especializado e/ou mais experiente, visto ser um processo de aprendizagem que não se acaba. A aprendizagem da autonomia pelo sujeito constitui-se como uma espiral, na qual o impulso para aprender favorece a busca livre para outras novas aprendizagens. Ela é um processo que não se esgota e se amplia a cada novo desafio.

Segundo nossas colaboradoras, ser um sujeito autônomo significa ser alguém com autenticidade, que não é reprodutor do dito do outro, é ser alguém produtor dos seus próprios ditos. Assim, é um sujeito que consegue justificar suas escolhas, sabe esclarecer as razões e caminhos escolhidos. Por essa razão, esse sujeito necessita compreender os motivos que o levam a tomar determinadas decisões. Nesse sentido, a autonomia não é simplesmente fazer o que deseja.

\section{4 | CONSIDERAÇÕES FINAIS}

Para compreender constituição autonomia das estudantes de mestrado e doutorado em suas investigações, buscamos identificar o percurso da atividade de estudo de cada sujeito envolvido neste trabalho investigativo, durante a elaboração de suas pesquisas e conhecer quais ações e operações estavam envolvidas no processo de constituição de sua autonomia na pesquisa. Assim, evidenciamos aspectos que constituíram duas 
tensões ${ }^{1}$, as quais no nosso entender influenciaram significativamente no processo de elaboração da autonomia das colaboradoras para a produção de suas investigações mediante a experiência da atividade de pesquisa, são elas: percurso da pesquisa e construção da autonomia, tempo de aprendizagem pessoal e tempo instituído para a pesquisa.

A primeira tensão, percurso da pesquisa e construção da autonomia, consistiu no movimento latente entre o que o sujeito precisou pesquisar, isto é, as metas da atividade de pesquisa que objetivava alcançar e o domínio do conhecimento cognitivo e operacional que possuía sobre o objeto em estudo, de forma a ser capaz de produzir conhecimento sobre ele com autonomia. A clareza e compreensão sobre as necessidades e os motivos que as levaram a investir em um processo de produção da pesquisa, auxiliaram cada uma das colaboradoras no planejamento das ações e operações, bem como as ajudaram no momento da autoavaliação e da autorregulação dessa atividade de pesquisa. Porém, tais aspectos que compõem essa produção não foram facilmente conquistados por elas, ao contrário, requereu delas uma postura de abertura e humildade para perceberem suas limitações e procurarem auxílio. Chamamos esse período de tomada de consciência de suas limitações de momento de ruptura.

Os momentos os quais exigiram rupturas, por parte das colaboradoras, foram provocados, essencialmente, a partir das seguintes situações: a resistência em reelaborar o que parecia pronto, a abertura para novas possíveis mudanças no processo original de tese, o diálogo presente entre orientadora e orientandas, o compartilhamento de conhecimentos durante as reuniões coletivas do grupo de estudo e pesquisa.

Ainda sobre a tensão entre o percurso da pesquisa e a construção da autonomia, evidenciamos que a configuração do trabalho grupal constituiu-se como forma de organização da prática de pesquisa, uma vez que a realização dos estudos no grupo permitiu modos de interação e mediação capazes de aprimorar as pesquisas tanto as individuais quanto a coletiva. $\mathrm{O}$ trabalho grupal também foi outro aspecto que as auxiliou na constituição da autonomia. Porém, a escrita do relatório de pesquisa, constituiu-se em um dos maiores desafios enfrentados pelas colaboradoras.

A parceria entre a orientadora e a orientanda foi fundamental para amenizar a tensão percurso da pesquisa e a construção da autonomia, visto que contribuiu para a promoção da segurança, autoafirmação, superação das limitações e a promoção das potencialidades; bem como o próprio momento de orientação tornou-se gerador de novas atividades de pesquisa. A constante dinâmica e tensão estabelecida entre liberdade e livre arbítrio frente às decisões que as colaboradoras tinham que fazer foram aspectos que influenciaram significativamente no processo de construção da autonomia na pesquisa. Nesse sentido, os principais resultados dessa tensão foram: a tomada de consciência das limitações e dos potenciais já adquiridos e aqueles que ainda tinham por desenvolver. Isso requereu dos sujeitos romper com suas concepções iniciais e se abrirem para novas aprendizagens e, por fim, a transformação de si se constituiu a partir das reflexões sobre os fatores que levaram aos êxitos e/ou aos equívocos dos sujeitos durante seus percursos de pesquisa.

A segunda tensão destacada é o tempo de aprendizagem pessoal e tempo instituído para a pesquisa. Ela tem como característica principal o constante conflito entre o tempo acadêmico e o tempo pessoal, os quais são responsáveis pelo desequilíbrio e contradições manifestados pelas

\footnotetext{
${ }^{1}$ Compreendemos por tensões, nesse estudo, alguns aspectos constantemente latentes, na dinâmica do processo de produção da pesquisa e autonomia na pesquisa, os quais não se resolvem instantaneamente, ao contrário, requer um processo de aprender a aprender, de aprender a fazer e de aprender a ser constante.
} 
colaboradoras durante suas atividades de pesquisa. Isso porque compreendemos que o gerenciamento da aprendizagem, nesse tipo de atividade, requer tempo além do tempo institucionalmente previsto e exigido. Contudo, o processo de tomada de consciência das limitações e das potencialidades e as transformações de si são, normalmente, prejudicados pelo tempo restrito instituído pela academia. Instalam-se, com isso, momentos de contradição e insegurança nas colaboradoras, visto que é necessário produzir resultados e o relatório de pesquisa em um prazo fechado.

Nessa perspectiva, evidenciamos que a construção da autonomia pelos sujeitos pode ser significativamente influenciada pela tensão entre o tempo pessoal e institucional, pois ela exige condições, não só para as aprendizagens cognitivas e procedimentais, mas, também, tempo para que o sujeito elabore para si essas novas apropriações. As exigências e as expectativas em relação a produção de novidade no campo investigativo que são impostas institucionalmente, em especial, aos estudantes do doutorado, junto às exigências e expectativas interiores destes próprios sujeitos, configuram-se nos motivos de sofrimento durante o processo da produção da pesquisa e na construção de suas autonomias.

Para aliviar a tensão existente entre esses dois tempos: o pessoal e o institucional, evidenciamos a necessidade do estabelecimento de uma disciplina e de uma rotina de trabalho, as quais se caracterizaram como imprescindíveis para que nossas colaboradoras se mantivessem focadas na atividade de produção das suas pesquisas. Mais uma vez, em virtude do fator tempo, o sujeito se rende e deixa latente a sua autonomia, pois necessita concluir as ações e operações da atividade de pesquisa dentro de um reduzido período. Como exemplo, foi o que ocorreu com uma das colaboradoras quando, ao final de sua escrita de relatório precisou efetivar as ações e operações quase que totalmente sob a tutela de sua professora-orientadora, posto que não havia mais tempo hábil para compreender as solicitações de melhoras na escrita e concretização da tarefa. Emergiu de sua narrativa que ela compreendeu a dimensão e o funcionamento das ações e das operações realizadas somente depois de finalizar o seu relatório de pesquisa.

Assim, mais uma vez podemos inferir que a relação entre tempo pessoal e tempo institucional é algo que influenciou significante, na constituição da autonomia dos sujeitos. A partir do exposto, compreendemos que para constituir a autonomia é necessário oferecer, não só condições para as aprendizagens cognitivas e procedimentais, mas também tempo para que o sujeito elabore para si essas novas apropriações. Assim, se a autonomia para pesquisa requer que o sujeito seja capaz de gerenciar sua aprendizagem e se a autonomia precisa de tempo para ser apreendida, é possível dizer que o gerenciamento da aprendizagem também requer tempo.

Na Pós-graduação stricto sensu, almeja-se que os sujeitos tenham a autonomia, porém ainda é um desafio a ser superado, posto ser uma aprendizagem que continua por toda a vida. Com isso podemos considerar que ela ainda é um dos principais desafios nesse nível de ensino. Desse modo, a aprendizagem da autonomia exige que o sujeito tenha consciência sobre seus próprios processos de aprendizagem, pois somente assim é possível ser capaz de autorregular seu desenvolvimento cognitivo. A autorregulação acontece devido ao processo de tomada de consciência das limitações e das potencialidades e as transformações de si. Porém, a constituição pelo sujeito dessas duas categorias, normalmente, é prejudicada pelo tempo restrito instituído pela academia, ou seja, pelos órgãos que regulam os Programas de Pós-graduação stricto sensu.

Diante dos achados desse estudo, é necessário inferir que os modos particulares de produzir a pesquisa levam o sujeito a gradativamente construir sua autonomia também de forma particular, a qual, por sua vez, não se consolida após o término da investigação. Isso corrobora o que inicialmente apresentamos sobre a autonomia como algo a ser apreendido pelo sujeito ao longo da vida, sendo a atividade de pesquisa um dos meios para sua constituição. Ressaltamos que esse 
CONSTITUIÇÃO DA AUTONOMIA | Gislaine A. R. da Silva Rossetto e Doris Pires Vargas Bolzan

estudo é uma possibilidade de entendimento do que seja o processo de produção da pesquisa e a constituição da autonomia, tendo como mote a atividade de pesquisa. Porém, estamos conscientes de que outros modos de compreender o processo de produção da pesquisa e constituição da autonomia na pesquisa podem ser delineados, como também outras categorias e elementos são possíveis de serem encontrados a partir de outras dinâmicas de pesquisas. 


\section{Referências}

BOLZAN, D. P. V. Formação de professores: construindo e compartilhando conhecimento. Porto Alegre: Mediação, 2002.

Aprendizagem docente reflexiva. In: MOROSINI, M. C. (Org.). Enciclopédia de pedagogia universitária, glossário. [S.I.: s.n.], 2006. v. 2. p. 378.

BOLZAN, D. P. V. et al. Pedagogia universitária: movimentos construtivos da docência no ensino superior. In: ENCONTRO DE PESQUISA EM EDUCAÇÃO DA REGIÃO SUL, 8, 2010, Londrina. Anais... Londrina: ANPED SUL, 2010.

DAVÍDOV, V.; MÁRKOVA, A. La concepción de la actividade de estúdio de los escolares. In: DAVÍDOV, V.; SHUARE, M. (Org.). La psiologia evolutiva y pedogógica en la URSS. Moscou: Progresso, 1987. p. 316-337.

FREITAS, M. T. A. A perspectiva sócio-histórica: uma visão humana da construção do conhecimento. In: FREITAS, M. T. A; SOUZA, S. J.; KRAMER, S.(Org.). Ciências humanas e pesquisa: leituras de Mikhail Bakhtin. São Paulo: Cortez, 2003. p. 57-76.

HEGEL, G. W. F. Linhas fundamentais da filosofia do direito, ou, direito natura e ciência do estado em compêndio. São Leopoldo: Ed. UNISINOS, 2010.

KANT, I. Resposta à pergunta: o que é o esclarecimento? Tradução Luiz Paulo Rouanet. Königsberg, Prússia: [s.n.], 1783. Disponível em: <http://ensinarfilosofia.com. brl__pdfs/e_livors/47.pdf>. Acesso em: 25 jan. 2013.

LEONTIEV, A. N. El surgimiento de la conciencia del hombre. In: VYGOTSKI, L. S. et al. El proceso de formacion de la psicologia marxista: L. Vygotski, A. Leontiev, A. Luria. Moscou: Progresso, 1989.
MARTÍN, E. Conclusiones: un currículo para desarrollar la autonomia del estudiante. In: MONEREO, C.; $\mathrm{POZO}$, J. I. La universidad ante la nueva cultura educativa: enseñar y aprender para la autonomia. Universidade Autónoma de Barcelona. Editorial Sintesis. s/d.

MARTINS, A. M. Autonomia e educação: a trajetória de um conceito. Cadernos de Pesquisa, n. 115, p. 207232, mar. 2002.

MONEREO, C.; POZO, J. I. La universidad ante la nueva cultura educativa: enseñar y aprender para la autonomia. Barcelona: Editorial Sintesis, [200-?].

RossetTO, G. A. R. S. Atividade de estudo e autonomia no processo de produção da pesquisa. 2013. Tese (Doutorado em Educação) - Universidade Federal de Santa Maria, Santa Maria, 2013.

SOARES, S. R.; CUNHA, M. I. Formação do professor: a docência universitária em busca de legitimidade. Salvador: EDUFBA, 2010. v. 1000.

VYGOTSKY, L. S. Obras escogidas I: incluye el significado histórico de la crises de la psicología. Madrid-España: Visor, 1997.

. Pensamiento y lenguaje. Madrid-España: Paidós Ibérica, 2010.

WEBER, T. Pessoa e autonomia na filosofia do direito de Hegel. Veritas, Porto Alegre, v. 55, n. 3, p. 59-82, set./dez. 2010. 